\title{
Functional Bowel Obstruction
}

National Cancer Institute

\section{Source}

National Cancer Institute. Functional Bowel Obstruction. NCI Thesaurus. Code C101033.

The blockage of bowel contents from evacuation; the causes are attributable to nonstructural impediments, such as chemical imbalances or the side effects of medications, narcotics in particular. 